\title{
COMPARISON AND ANALYSIS OF HEALTH CARE DELIVERY SYSTEM: PAKISTAN VERSUS CHINA
}

\author{
Shaista Taufiq Meghani, Sana Sehar \& Neelam Saleem Punjani \\ Aga Khan University School of Nursing and Midwifery. Karachi, Pakistan. \\ Corresponding Author Email: rajani_shaista@hotmail.com
}

\begin{abstract}
Healthcare delivery system is an arrangement that serves best to any country's population with effective, efficient and fair distributions of resources, and funds through organized infrastructure to thrive well. Better health improves country's labor force and ultimately raises human welfare and economic stability. This healthy labor force and productive human capital resources can be attained through structured healthcare facilities by the government for its people. Globally, health sectors varies from country to country and it depends on how much expenditures on health is been effectively utilized. In majority of the developing countries, private healthcare sectors, donor, and out of pocket expenditures are the primary contributors in health care services that may raise human capital and economic growth of the country. Whereas, public health sectors remains underprivileged due to structural fragmentation, lack of resources, and functional inabilities. This paper is mainly going to discuss about health care delivery system of Pakistan in comparison to China followed by organizational structure, analysis of both the healthcare systems, and some recommendations to improve healthcare reform and its utilization.
\end{abstract}

KEY WORDS

Health care system, Pakistan, China, Organizational structure, Healthcare reform

\section{INTRODUCTION}

\section{PAKISTAN'S HEALTH CARE DELIVERY SYSTEM}

Pakistan was inherited with the health care system initiated by the British government since 1947. The system is mainly responsible for preventing disease and provision of curative services to its population. In Pakistani constitution, provincial government is primary responsible for healthcare delivery and its management of the country, and the implementation of national policies. However, Federal government is responsible for planning and formulating national policies, research, training, and seeking foreign assistance (Nishter, 2006). Moreover, in recent times federal domain just looks at the accessibility of supplies and technology but not focusing on health at all. The healthcare system in Pakistan has both public and private health facilities, including government (public) and private hospitals, clinics, homeopaths, Hakeem's (Muslim physicians), traditional/spiritual healers, herbalists, bonesetters, and quacks. Public sector has Primary Health Care (PHC) facility comprises of Basic Health Units (BHU) and Rural Health Centers (RHC). Tehsil Headquarters hospitals accommodate population at sub district level and District Headquarters hospitals cater district population. In addition, tertiary health care facilities are also available that are mainly located in cities and serves as teaching hospitals. There are other autonomous organizations such as Pakistan Army, railways departments of local government, provides healthcare facilities to their employees. Only $30 \%$ of the population utilizes the services of PHC and the reasons are less staff especially women, poor service quality and inconvenient PHC locations. The public healthcare sector has multiple problems with inefficiency, unavailability of resources, poor infrastructures and gender insensitivities (Sheikh, 2010). Public sector is mainly financed through external or overseas funding. It contributes only $23 \%$ of total expenditure on health. In contrast, private sector contributes $77 \%$ of health expenditure. It means that total 3 to $4 \%$ of GNP is spend on health, with 2 to $3 \%$ of GNP is spend on private healthcare sectors (Sheikh, 2010). "Pakistan spends $\$ 17$ per capita on health, and $\$ 13$ of this amount comes from out-of-pocket expenses" (Islam, 2002). The government of Pakistan and other developmental agencies like NGOs always strive for public private partnership but there is no well defined strategy to regulate both. However, the unregulated private healthcare facilities have some illegal and unethical issues such as mal practice of healthcare professionals, over charging patients, unnecessary prescriptions of medications and laboratory test without any indications and so on. Several studies has concluded that the overall utilization of private healthcare facility is $80 \%$ whereas $20 \%$ is from public healthcare facilities by the population.

\section{CHINA'S HEALTH CARE DELIVERY SYSTEM}

China's health care system is managed by ministry of health and local government that is hospital based delivery system. Interestingly, china's inpatient services have largest provision of health expenditure. In 2003, there was $68.88 \%$ health expenditure whereas in 2010 , it has slightly reduced to $61.61 \%$. Previously, China's population only had an access to basic healthcare facilities through cooperative medical schemes (CMS) which was managed by agriculture communities. The growing urban population had an access to health insurance either by labor insurance or the Government insurance system (Eggleston, 2012). China's health care system has transformed together with china's society and economy. Recently, China's health care system is government owned and focusing mainly on primary health care system of "grass root providers" to improve quality and funding for village clinics, township health centers, and urban community centers (Eggleston, 2012). China is also facing the issue of inaccessibility of primary healthcare services and quality of healthcare providers in rural areas by its population but it does not have any challenge to lack of healthcare providers, absenteeism and disintegrated infrastructure like other developing countries. The larger share of services is provided by private sector at the grass root levels including $18.6 \%$ of visits to community health centers and stations. Since chain's healthcare system has recently categorized as public and private therefore, it is difficult to state how much private sector 
has grown (Eggleston, 2012). China was also facing an issue of out of pocket expenditure. To overcome this issue, in 2009 government of china had announced social health insurance coverage. This is how china has tried to achieve its five articulated goals of 2009-2011by extending insurance coverage to $90 \%$ of its population, public health service benefit package, and improving primary care services (Eggleston, 2012).

\section{ORGANIZATIONAL ENVIRONMENT OF BOTH THE HEALTHCARE SYSTEM}

\section{GOALS AND EXPECTATIONS.}

Pakistan's healthcare system failed to achieve goals of "Health for All" in Alma Ata Declaration and thus followed to attain Millennium Developmental Goals (MDGs) 2015. Some of the targets were focused on health care such as reducing child mortality rate, improving maternal health, and combating HIV/AIDS, malaria, and other diseases. Despite having goals and targets, Pakistan still has showed slow and dissatisfactory progress and it is unlikely that Pakistan may achieve these deadlines due to scarce resources, structural mismanagement and inadequate financing (Sheikh, 2012). Similarly, china is also focusing to attain MDGs 2015 for which government of china has reformed its healthcare system and health policies. China is striving to reduce poverty, child mortality, HIV/AIDS, and other disease, empowering women, and promoting education like Pakistan. China has targeted its five major goals in 2009 to 2011 which include $90 \%$ of the population has basic health insurance, public health service packages, primary care is strengthened, development of essential drug list, and experimenting with reforms of government -owned hospital (Eggleston, 2012).

\section{RESOURCES AND TECHNOLOGY.}

Pakistan is facing issues in terms of scarce resources, structural mismanagement and inadequate financing. Government only spends $0.6 \%$ GDP on health. National health policies are formulated based on political inferences rather than evidence of required need (Shiekh, 2012). Pakistan is in critical stage of workforce deficiency. This deficiency is stagnant due to lack of financial resources, scarce healthcare professionals, and migration of skilled workers. Similarly, china is also facing shortage of nurses and physicians and this scarcity of workforce led poor delivery of health services. Health care services are well equipped in both countries but, they are underutilized due to untrained health care professional and the availability of technology is beyond the scope of health care facility. China has are very limited in numbers of PHC centers and are not well equipped according to the scope and function of PHC. However, china is striving to advance its technology and pharmaceutical companies that are the source of earning for china (Eggleston, 2012).

\section{ANALYSIS OF BOTH THE HEALTHCARE SYSTEM}

This section is mainly focus on the comparative analysis of both the healthcare system based on the conceptual framework which is developed in 2003 by Hsiao (Appendix 1).

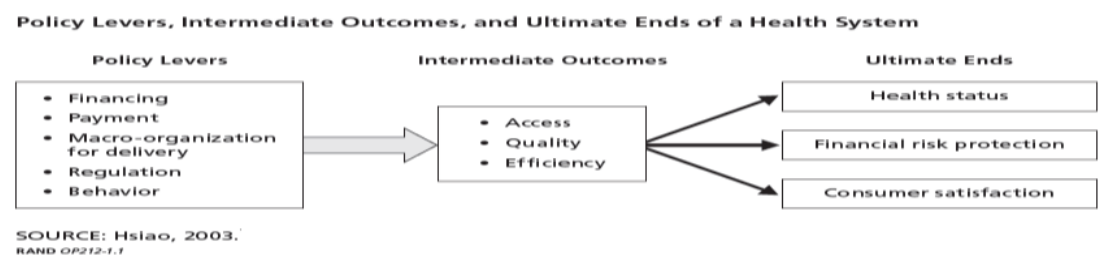

\section{POLICY LEVERS}

\section{FINANCING}

Pakistan is the poor country with burden of the debt servicing of $43 \%$. $7 \%$ is spent on defense due to undue tension on border and terrorism. Hence, only $3.1 \%$ of GDP is allocated for economic, social and community services, out of which only $0.8 \%$ is spent on healthcare (Shaikh, 2004). Pakistan spends $85 \%$ of its health care budget on tertiary healthcare that is used by about $15 \%$ of the population and leftover $15 \%$ is used by $85 \%$ of population on primary health care (Islam, 2002). On contrary to this, China allocates $5.6 \%$ to its budget. China spends $35 \%$ of its budget on the primary health and $65 \%$ of its budget on the secondary and tertiary health care (Shanlian, 2008). Both the countries have similar health expenditure and outcome a decade ago. China has felt dearth need to change its shift of expenditure on primary health after the new china health reforms.

\section{PAYMENT}

Payment describes how money, once raised, is spent: who to pay, what to pay for, and how much to pay (Ma, 2008). Both the countries have less social security system which makes the poor more vulnerable in terms of affordability and choice of health care professionals. $76 \%$ goes out of pocket cost (OPC) in general population is a certain barrier in seeking health care (Shaikh, 2004). Transportation to the health facility and other additional charges spend for the treatment make the consultation more distressing. Khan (2009) reported that more than $1 / 3$ of women did not know the cause of their illness, due to lack of exposure to the world outside the home. Lewis (2006) reports several studies that average payment to hospital visit is US\$16-36, with referral it raises to average US\$44. This is roughly $90 \%$ of half monthly income. Hence, lack of insurance coverage of the population has disturbed equity and availability of public health resources to the population who belong to lower socio-economic status.

\section{REGULATIONS}

Regulation refers to the government's use of coercive power to impose a full range of legal constraints (Ma, 2008). Corruption in 
all level of the health care is the major cause of malfunction in Pakistan. Absenteeism of doctors and staff is out of control. Doctor or a staff member who does not want to come to BHU simply shares a portion of their salary with executive district health officer (Khan, 2009). In china too, under cooperative medical systems huge local cadres enjoyed preferential treatments and favorable reimbursement of large medical bills and the needy are deprived (Chereches, 2013). Pakistan is on 2nd position among all countries with population perceiving high levels of corruption in many health reports (Lewis, 2006). The population is expected for informal payments at the public health care facilities. Similarly, in China "unofficial fees" and "red packets" are the common phenomenons for general public Average 30\% of public drug supplies are expired, suggesting poor management and limited supervision (Chereches, 2013).

\section{MACRO-ORGANIZATION}

Organization refers to the broad structure that organizes health care including ownership, market competition, decentralization (Ma, 2008). In Pakistan the devolution plan of health came in 1999. According to the plan, the local government is based on the fundamentals of devolution of political power, decentralization of administrative authority, and distribution of resources to the district level (Islam, 2002). Despite the decentralization and authority to local government, health care system has become worse because of inefficiency of the public health care system. Moreover, private sector comprises of $72 \%$ with the average uptake of the patient more than $70 \%$ in routine and $80 \%$ of the patients visit first time to the private practitioner on illness because of inaccessibility of the healthcare professionals and resources in public sector (Uplekar, 2001). In 2000, the central China issued first regulation concerning non-profit and for-profit health care organizations (Lee, 2012). Today, although China's economy as a whole is dominated by the private sector, the private sector's role in health care is still limited. By 2002, there were more than 200,000 private practitioners, representing about $4 \%$ of the total 5.2 million health professionals in China; most of these private practitioners were located in rural areas and has played the key role in health improvement (Ma, 2008).

\section{INTERMEDIATE OUTCOMES}

\section{ACCESS}

Access, here defined as effective availability, measures how easy it is for people to overcome barriers e.g., physical, social, and financial barriers, timing, and service availability obstacles to get care (Ma, 2008). In Pakistan, dissatisfaction with primary care services lead many to tertiary care hospitals for primary care hence, considerable inefficiency and loss of control over efficacy and quality of services occurs (Shaikh, 2004). China is also facing issue of inaccessibility of primary healthcare services and quality of healthcare providers in rural areas but not observes challenges in terms of lack of healthcare providers, absenteeism and disintegrated infrastructure like Pakistan.

\section{QUALITY}

Routine evaluation and assessment of quality is an important part of a health system, and indicators are underuse of public health services and supply induced overutilization of technologies (Ma, 2008). In Pakistan, only $30 \%$ of the population utilizes the services of PHC and reasons are less staff especially women, poor service quality and inconvenient PHC locations. Moreover, inefficiency, unavailability of resources, poor infrastructures and gender insensitivities exacerbate the situation (Sheikh, 2010). China has now achieved universal coverage with 1.295 out of 1.3397 billion people ( $95 \%$ of the population) has health insurance, and out of pocket spending is $35.5 \%$ (Eggleston, 2012). The system continues to have many weaknesses in providing access to quality services. Thereafter China is maximally utilizing its resources with the only challenge is to strengthen more its primary health care (Eggleston, 2012).

\section{EFFICIENCY}

The efficiency of a health system is determined by the degree to which system maximizes health-status gain cost effectively. China has developed multiple agencies equivalent to U.S. Centers for Disease Control and Prevention (CDC). Aiming to improve disease surveillance incorporated at all levels of governments. Moreover, for further improvement some local and provincial CDCs have attempted to establish their own "national" capacity (Ma, 2008). This enables the government to have synergic implementation at horizontal and vertical approach in promoting health. Devolution of the federal government, the national level integration programs had been demolished and come under the provincial government which has created the discrepancies in many program e.g., immunization and lady health workers. Moreover, corruption is the root cause of ineffective utilization of money in Pakistan (Ahmed, 2008).

\section{ULTIMATE ENDS}

\section{CONSUMER SATISFACTION AND HEALTH STATUS.}

In China patients at public facility are satisfied with hospital environment but dissatisfied with ability to build relationships whereas, in private facility the high fees bring dissatisfaction (Eggleston, 2012). Similarly, in Pakistan among patients with acute illness only $21 \%$ seek care at a public sector at first-level, and reason is lack of quality care. Moreover, private facility has compromised care too thereafter, consumer dissatisfaction is so high and affecting the health seeking behaviors of the population (Shaikh, 2008). Consumer satisfaction prospects into health status of the population. For example, people in China lives longer and healthier than people in Pakistan. In Pakistan, life expectancy of woman is 67.7 years, whereas in China its 74 years. A man born in Pakistan has life expectancy of 65.5 years, whereas in China its 70 years. (Lee, 2012).

\section{FINANCIAL RISK PROTECTION}

Poor health is associated with worse physical, social and mental well-being. Extensive research has shown that poor health can also increase poverty and reduce material well-being through a number of paths including excessive medical expense, impaired labor market participation, and loss of productivity. In China, $25 \%$ of the surveyed households had to borrow money and that another $6 \%$ had to sell their assets to pay for health care (Ma, 2008). Whereas, in Pakistan most common types of shocks are health related which 
comprises $55 \%$ of the total. These health shocks can be natural disasters or man-made which take a heavy percentage that shares the household expenditure burden, and in consequence the populations reports poverty, unemployment, poor health and shelter, communicable diseases, food shortage, school dropouts, and or child labor (Heltberg, 2009). Hence Pakistani observes more serious health shocks as compared to Chinese.

\section{CHALLENGES FACED BY PAKISTANI HEALTHCARE SYSTEM}

- Pakistan healthcare system is facing lack of administrative capacity and accountability at government level, political instability and bureaucratic resistance. Selections of leaders are made on personal and political grounds

- Lack of power and authority delegation at district and sub district level

- Allocation of budget and resources are not need- based and there is an extra burden of non-developmental funds.

- Healthcare professionals are untrained, underpaid and deprived of needed facilities in order to practice.

- Lack of transport facility for the population in order to access healthcare and emergency referrals

\section{RECOMMENDATIONS}

- Strengthening and empowering the role of state leaders

- Appropriate utilization of public funds and organization of priority services to be provided universally

- Developing substitute service delivery and financing options at the basic healthcare and hospital levels.

- Granting autonomy at management level and introducing costsharing at the level of financing

- Building the capacity and effectively deploying human resource to improve career structure of all healthcare professional

- Establishing a rewarding working environment and initiating measures to restore imbalances with regard to existing staff

- Building conscious protection in order to balance the risk of creating access and affordability issues for the poor in new service delivery arrangements

- Establishing Public-Private partnership in order to foster arrangements that bring organizations together

- Establishment of social health insurance as part of a comprehensive social protection

- Effective management and monitoring of healthcare system should be owned by district government and thus maintains the standards

- Government should introduce such environment and policies for research and development in medical sciences to promote knowledge creation and growth.

- Provision of primary health care is required with cost effective strategies for increasing population to sustain long term positive impact on health status on the population.

\section{CONCLUSION}

This paper highlighted health care delivery system of Pakistan in comparison to China followed by organizational structure, analysis of both the healthcare systems, and recommendations to improve healthcare reform and its utilization. Health cannot be separated from political, economic, social and human development contexts. Gaps at government level, poor system regulation, lack of efficiency and resources, breaks in social justice cannot be excluded from macroeconomic and social development of Pakistan. Therefore, Sustainable growth and improvement at the government level need to be addressed for structural and operational changes in health care system in order to break the cycle of corruption and underdevelopment.

\section{REFERENCES}

- Ahmed, J., \& Shaikh, B. T. (2008). An All Time Low Budget for Healthcare in Pakistan. Journal of the College of Physicians and Surgeons Pakistan, 18(6), 388-391.

- Cherecheş, R. M., Ungureanu, M. I., Sandu, P., \& Rus, I. A. (2013). Defining informal payments in healthcare: A systematic review. Health Policy, 110(2), 105-114.

- Eggleston, K. (2012). Health Care for 1.3 Billion: An Overview of China's Health System. Stanford Asia Health Policy Program Working Paper No. 28

- Heltberg, R., \& Lund, N. (2009). Shocks, Coping, and Outcomes for Pakistan's Poor: Health Risks Predominate. The Journal of Development Studies, 45(6), 889-910.

- Islam, A. (2002). Health Sector Reform in Pakistan: Future Directions. Journal of Pakistan Medical Association.

- Khan, M. A. (2009). Failure Analysis of Primary Health Care in Pakistan \& Recommendations for change. Islamabad: Insaf Research Wing.

- Lee, M., Shiroma, E. J., Lobelo, F., Puska, P., Blair, S. N., \& Katzmarzyk, P. T. (2012). Effect of physical inactivity on major non-communicable diseases worldwide: an analysis of burden of disease and life expectancy. The Lancet, 380.

- Lewis, M. (2006). Governance and corruption in public health care systems. Washington, DC: Center for Global Development. No. 78

- Ma, S., \& Sood, N. (2008). A comparison of the health systems in China and India. Rand Corporation. Vol. 212

- Shaikh, B. T., \& Hatcher, J. (2004). Health seeking behaviour and health service utilization in Pakistan: challenging the policy makers. Journal of Public Health, 27 (1), 49-54

- Shaikh, B. T., Mobeen, N., Azam, S. I., \& Rabbani1, F. (2008). Using SERVQUAL for assessing and improving patient satisfaction at a rural health facility in Pakistan. Eastern Mediterranean Health Journal, 14( 2), 447-455.

- Shanlian Hu, M., Tang, S., Liud, Y., Zhaoe, Y., Escobar, M.L., \& Ferranti, D. d. (2008). Reform of how health care is paid for in China: challenges and opportunities. The Lancet, 372(9652), 1846-1853.

- Sheikh, B. T., Rabbani, F., Safi, N., \& Dawar, Z. (2010). Contracting of primary health care services in Pakistan: Is upscaling a pragmatic thinking? The journal of the Pakistan Medical Association, 60(5), 387.

- Uplekar, M., \& Raviglione, M. (2001). Private practitioners and public health: weak links in tuberculosis control. The Lancet,358,912-917. 
